\title{
A good response to glucocorticoid for sub-acute liver failure: a case report
}

\author{
Zhaohui Bai ${ }^{1,2,3 *}$, Hongyu Li ${ }^{1 *}$, Kexin Zheng ${ }^{1,4 *}$, Jingqiao Zhang ${ }^{2,3}$, Xintong Zhang ${ }^{1}$, Jiao Deng ${ }^{2}$, Zhe Jia $^{5}$, \\ Xinmiao Zhou ${ }^{4}$, Xiaozhong Guo ${ }^{1}$, Xingshun $\mathbf{Q i}^{1}$ \\ ${ }^{1}$ Department of Gastroenterology, ${ }^{2}$ Department of Pharmacology, General Hospital of Shenyang Military Area, Shenyang 110840 , China; \\ ${ }^{3}$ Postgraduate College, Shenyang Pharmaceutical University, Shenyang 110840, China; ${ }^{4}$ Postgraduate College, Jinzhou Medical University, Jinzhou \\ 121001, China; ${ }^{5}$ Section of Medical Service, General Hospital of Shenyang Military Area, Shenyang 110840, China \\ *These authors contributed equally to this work. \\ Correspondence to: Dr. Xingshun Qi, MD; Prof. Xiaozhong Guo. Department of Gastroenterology, General Hospital of Shenyang Military Area, No. \\ 83 Wenhua Road, Shenyang 110840, China. Email: xingshunqi@126.com; guo_xiao_zhong@126.com.
}

\begin{abstract}
Liver failure is a severe clinical syndrome presenting with coagulation dysfunction, jaundice, hepatic encephalopathy, and ascites. It often has a dismal prognosis. The role of glucocorticoid for the treatment of liver failure is unclear. In this paper, we reported that a female patient with sub-acute liver failure had a good response to glucocorticoid.
\end{abstract}

Keywords: Liver failure; drug-induced liver injury; methylprednisolone

Received: 17 March 2018; Accepted: 16 April 2018; Published: 03 May 2018.

doi: $10.21037 / \operatorname{tgh} .2018 .04 .07$

View this article at: http://dx.doi.org/10.21037/tgh.2018.04.07

\section{Introduction}

Liver failure is mainly divided into three categories, including acute liver failure, acute-on-chronic liver failure, and acute decompensated end-stage liver disease, according to the international consensus and practice guidelines (1). Diagnostic criteria for sub-acute liver failure are also defined according to the Chinese practice guideline. During the past 226 weeks, a patient with sub-acute liver failure should have the following performances: (I) extreme weakness and obvious gastrointestinal symptoms; (II) worsening of jaundice, total bilirubin (TBIL) higher than the upper limit of normal 10 times or a rise $\geq 17.1 \mu \mathrm{mol} / \mathrm{L}$ per day; (III) with or without hepatic encephalopathy; and (IV) significant bleeding tendency, define as plasma prothrombin activity $\leq 40 \%$ or international standardization ratio (INR) $\geq 1.5$ (reference range: $0.9-1.1$, and exclusion of other causes for bleeding tendency (2). Sub-acute liver failure is further divided to early, middle and advanced stage according to the disease severity and progression. Till now, the role of glucocorticoid for the treatment of liver failure remains unclear $(2,3)$. In this paper, we reported an old female patient with sub-acute liver failure who achieved a good response to methylprednisolone.

\section{Case presentation}

On February 10, 2017, a 76-year-old previously healthy female presented with worsening of yellowish skin and sclera with intermittent fever for about 20 days. She had a 10-year history of hypertension and took telmisartan pills daily. She denied any history of smoking and drinking. She admitted to take unknown health care product between September and November 2016. At her local hospital, laboratory tests demonstrated that TBIL was $151.9 \mu \mathrm{mol} / \mathrm{L}$ (reference range: 5.1-22.2 $\mu \mathrm{mol} / \mathrm{L}$ ), direct bilirubin (DBIL) was $128.2 \mu \mathrm{mol} / \mathrm{L}$ (reference range: $0-8.6 \mu \mathrm{mol} / \mathrm{L}$ ), alanine aminotransaminase (ALT) was $977 \mathrm{U} / \mathrm{L}$ (reference range: 9-50 U/L), alkaline phosphatase (ALP) was $224 \mathrm{U} / \mathrm{L}$ (reference range: $45-125 \mathrm{U} / \mathrm{L}$ ), and $\gamma$-glutamyl transpeptidase (GGT) was $233 \mathrm{U} / \mathrm{L}$ (reference range: 10-60 U/L), prothrombin time (PT) was $16.6 \mathrm{~s}$ (reference range: 11.5-14.5 s), and INR was 1.34 (reference range: 0.9-1.1). Viral hepatitis was negative. Serum lipase and amylase were within the normal range. Abdominal CT scans showed cholecystitis and mild ascites. In spite of antibiotics, intermittent fever remained.

On February 14, 2017, she was transferred to 
our department. Laboratory tests demonstrated that TBIL was $267.0 \mu \mathrm{mol} / \mathrm{L}$, DBIL was $189.9 \mu \mathrm{mol} / \mathrm{L}$, ALT was $461.26 \mathrm{U} / \mathrm{L}$, aspartate aminotransaminase (AST) was $686.78 \mathrm{U} / \mathrm{L}$ (reference range: $15-40 \mathrm{U} / \mathrm{L}$ ), ALP was $156.92 \mathrm{U} / \mathrm{L}, \mathrm{GGT}$ was $200.31 \mathrm{U} / \mathrm{L}$, albumin (ALB) was $27.8 \mathrm{U} / \mathrm{L}$ (reference range: $40-55 \mathrm{~g} / \mathrm{L}$ ), PT was $19.5 \mathrm{~s}$, INR was 1.67 , C-reactive protein (CRP) was $32.0 \mathrm{mg} / \mathrm{L}$ (reference range: $0-8 \mathrm{mg} / \mathrm{L}$ ), procalcitonin (PCT) was $1.36 \mathrm{ng} / \mathrm{mL}$ (reference range: $0.114-0.287 \mathrm{ng} / \mathrm{mL}$ ). Hepatitis A, B, C, and E virus, Epstein-Barr virus antibody, and autoimmune related liver disease antibodies were negative. According to the RUCAM scale for drug induced liver injury, her score was 4 points ( $<0$ excluded; $1-2$ unlikely; $3-5$ possible; 6-8 probable; $>9$ highly probable). Thus, a diagnosis of subacute liver failure related to drug abuse was suspected.

She was initially treated with magnesium isoglycyrrhizinate $200 \mathrm{mg} /$ day, diisopropylamine dichloroacetate $80 \mathrm{mg} /$ day, adenosine methionine dimer sulfonate $1 \mathrm{~g} /$ day, and alanyl glutamine $10 \mathrm{~g} /$ day. On February 16, 2017, laboratory tests demonstrated that TBIL was $289.8 \mu \mathrm{mol} / \mathrm{L}$, DBIL was $208.1 \mu \mathrm{mol} / \mathrm{L}$, ALT was $488.76 \mathrm{U} / \mathrm{L}$, AST was $793.37 \mathrm{U} /$ L, ALP was $150.61 \mathrm{U} / \mathrm{L}$, GGT was $176.16 \mathrm{U} / \mathrm{L}$, ALB was 24.7 U/L, PT was $21.5 \mathrm{~s}$, and INR was 1.87.

After a consultation with her relatives, plasma exchange was performed on February 17, 2017 and February 19, 2017. However, liver and coagulation function parameters remained. On February 22, 2017, she presented with a sudden onset of unconsciousness with decreased ability of calculation and location. Laboratory tests showed that TBIL was $274.6 \mu \mathrm{mol} / \mathrm{L}$, DBIL was $187.7 \mu \mathrm{mol} / \mathrm{L}$, ALT was $301.21 \mathrm{U} / \mathrm{L}$, AST was $262.51 \mathrm{U} / \mathrm{L}$, ALP was 89.1 U/L and GGT was 83.4 U/L, ALB was 29.3 U/L, PT was 28.9 s, INR was 2.73 , and blood ammonia was $84 \mathrm{umol} / \mathrm{L}$ (reference range: 9-54 $\mathrm{mmol} / \mathrm{L})$. A diagnosis of hepatic encephalopathy was considered. Arginine and L-ornithine L-aspartate were given.

At that time, her relatives refused to continue plasma exchange. Instead, methylprednisolone was prescribed. Intravenous infusion of methylprednisolone sodium $40 \mathrm{mg} / \mathrm{d}$ was given for the first 7 days. Her consciousness became gradually improved. Laboratory tests demonstrated that TBIL was $250.1 \mu \mathrm{mol} / \mathrm{L}$, DBIL was $185.4 \mu \mathrm{mol} / \mathrm{L}$, ALT was $88.45 \mathrm{U} / \mathrm{L}$, AST was $35.82 \mathrm{U} / \mathrm{L}$, ALB was $24.7 \mathrm{U} / \mathrm{L}$ and blood ammonia was $64 \mu \mathrm{mol} / \mathrm{L}$, ALP was $90.67 \mathrm{U} / \mathrm{L}, \mathrm{GGT}$ was $78.53 \mathrm{U} / \mathrm{L}$, PT was $30.2 \mathrm{~s}$, and INR was 2.88 .

Thus, oral methylprednisolone was given. Its dosage was gradually decreased. Liver function parameters were also gradually reduced (Figure 1). On March 17, 2017, laboratory tests demonstrated that TBIL was $199.3 \mu \mathrm{mol} / \mathrm{L}$, DBIL was
$143.3 \mu \mathrm{mol} / \mathrm{L}$, ALT was $62.31 \mathrm{U} / \mathrm{L}$, AST was $43.11 \mathrm{U} / \mathrm{L}$, ALB was $30.2 \mathrm{U} / \mathrm{L}$, blood ammonia was $28 \mu \mathrm{mol} / \mathrm{L}$, platelet was $26 \times 10^{9} / \mathrm{L}$ [reference range: $(125-350) \times 10^{9} / \mathrm{L}$ ], ALP was $117.8 \mathrm{U} / \mathrm{L}$, GGT was $92.73 \mathrm{U} / \mathrm{L}, \mathrm{PT}$ was $22.8 \mathrm{~s}$, and INR was 2.01. Severe thrombocytopenia was considered. She was intravenously infused with platelets and clotting factors.

On March 28, 2017, the patient underwent magnetic resonance cholangiopancreatography. No bile duct abnormality was shown (Figure 2). On April 11, 2017, laboratory tests demonstrated that TBIL was $78.9 \mu \mathrm{mol} / \mathrm{L}$, DBIL was $55.4 \mu \mathrm{mol} / \mathrm{L}$, ALT was $54.35 \mathrm{U} / \mathrm{L}$, AST was $49.7 \mathrm{U} / \mathrm{L}$, ALB was $25 \mathrm{U} / \mathrm{L}$, blood ammonia was $21 \mu \mathrm{mol} / \mathrm{L}$, PLT was $37 \times 10^{9} / \mathrm{L}$, ALP was $86.59 \mathrm{U} / \mathrm{L}$, GGT was $50.02 \mathrm{U} / \mathrm{L}$, PT was $23.2 \mathrm{~s}$, and INR was 2.06. She was discharged on April 13, 2017 and continued oral methylprednisolone.

\section{Discussion}

The treatment of liver failure mainly includes comprehensive medical treatment, artificial liver support treatment, and liver transplantation (2). Liver transplantation is the only one effective choice of treatment for liver failure. However, only a few patients with liver failure can undergo liver transplantation due to its high cost and shortage of donor. Artificial liver support is an effective alternative $(2,3)$. Nakae et al. found that plasma exchange can improve the symptoms and signs of liver failure (4). In our patient with sub-acute liver failure, traditional hepato-protective drugs were initially employed, but no response was achieved. After that, plasma exchange remained unsatisfactory.

Currently, the use of glucocorticoid is controversial in such patients. An early meta-analysis showed that glucocorticoids were ineffective for the treatment of patients with alcoholic liver diseases (5). In 2009, the Asian Pacific Association for the study of the liver (APASL) guideline proposed that glucocorticoid might reactivate hepatitis $B$ virus in patients with hepatitis $B$ and liver failure (6). In 2004, it was reported that 7 patients with ocular diseases may develop liver failure after the use of glucocorticoid (7). By comparison, the 2005 guideline of American Association for the Study of Liver Disease (AASLD) regarding acute liver failure suggested that glucocorticoids could be considered for only autoimmune liver diseases (3). In 2012, the Chinese guideline regarding diagnosis and treatment of liver failure recommended that prednisone could be considered with a dosage of $40-60 \mathrm{mg} / \mathrm{d}$ for liver failure related to non-viral hepatitis (i.e., autoimmune hepatitis) and that glucocorticoid could be considered for early-stage liver failure caused by other factors, if liver failure rapidly progressed 



Figure 1 Changes of total bilirubin (TBIL), direct bilirubin (DBIL), aspartate aminotransaminase (AST), alanine aminotransaminase (ALT), alkaline phosphatase (ALP), and $\gamma$-glutamyl transpeptidase (GGT).

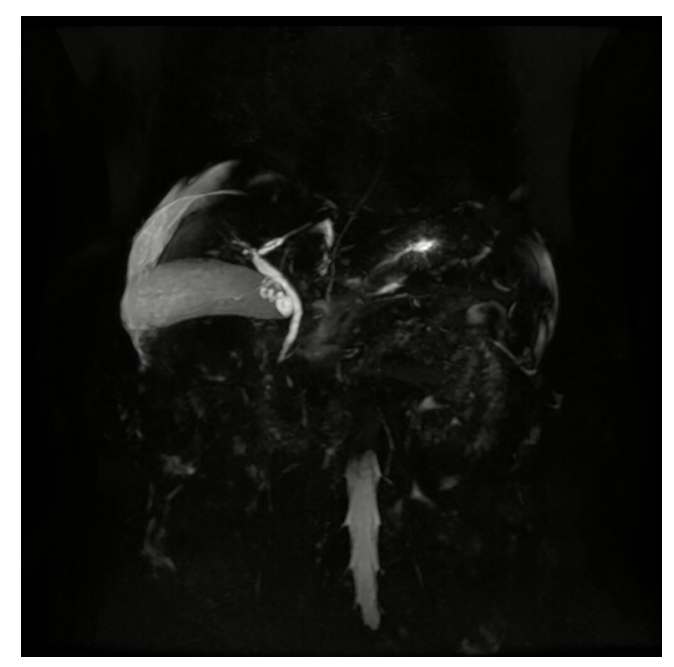

Figure 2 Magnetic resonance cholangiopancreatography.

without serious infection, bleeding, or other complications (2). Japanese researchers reported that 7 of 10 patients with liver failure treated with glucocorticoid had a satisfactory response (8).
Wu et al. also found that glucocorticoid can reduce the mortality of patients with sub-acute liver failure. The mortality was $25 \%$ in patients treated with glucocorticoid, while the mortality was up to $77.8 \%$ in those without glucocorticoid (9). When the liver function deteriorated rapidly and hepatic encephalopathy occurred in our patient, the patient was treated with glucocorticoid and achieved a good response.

In conclusion, a patient with sub-acute liver failure might have a good response to glucocorticoid therapy. Certainly, the effectiveness and safety of glucocorticoid for the treatment to sub-acute liver failure should be further explored in large studies.

\section{Acknowledgements}

None.

\section{Footnote}

Conflicts of Interest: The authors have no conflicts of interest to declare. 
Informed Consent: At the time of follow-up, the patient's relatives indicated that the patient died on August 5, 2017. This work has obtained oral consent from the patient's relatives.

\section{References}

1. Sarin SK, Kedarisetty CK, Abbas Z, et al. Acute-onchronic liver failure: consensus recommendations of the Asian Pacific Association for the Study of the Liver (APASL) 2014. Hepatol Int 2014;8:453-71.

2. Liver Failure and Artificial Liver Group, Chinese Society of Infectious Diseases, Chinese Medical Association, et al. Diagnostic and treatment guidelines for liver failure (2012 version). Chinese Journal of Hepatology 2013;21:177-83.

3. Polson J, Lee WM; American Association for the Study of Liver Disease. AASLD position paper: the management of acute liver failure. Hepatology 2005;41:1179-97.

4. Nakae H, Igarashi T, Tajimi K. Selective plasma exchange with dialysis in patients with acute liver failure. Ther

doi: 10.21037/tgh.2018.04.07

Cite this article as: Bai Z, Li H, Zheng K, Zhang J, Zhang X, Deng J, Jia Z, Zhou X, Guo X, Qi X. A good response to glucocorticoid for sub-acute liver failure: a case report. Transl Gastroenterol Hepatol 2018;3:25.
Apher Dial 2012;16:467-71.

5. Christensen E, Gluud C. Glucocorticoids are ineffective in alcoholic hepatitis: a meta-analysis adjusting for confounding variables. Gut 1995;37:113-8.

6. Sarin SK, Kumar A, Almeida JA, et al. Acute-on-chronic liver failure: consensus recommendations of the Asian Pacific Association for the study of the liver (APASL). Hepatol Int 2009;3:269-82.

7. Marinó M, Morabito E, Brunetto MR, et al. Acute and severe liver damage associated with intravenous glucocorticoid pulse therapy in patients with Graves' ophthalmopathy. Thyroid 2004;14:403-6.

8. Fujiwara K, Yasui S, Okitsu K, et al. The requirement for a sufficient period of corticosteroid treatment in combination with nucleoside analogue for severe acute exacerbation of chronic hepatitis B. J Gastroenterol 2010;45:1255-62.

9. Wu G, Wang W, Liu T. Clinical observation of glucocorticoid treatment of non-infectious sub-acute liver failure. Chinese Hepatology 2010;15:68-9. 